within the transfused serum of relatively stable components of complement (not lytic by themselves) in sufficient concentration to increase the haemolytic power of the patient's own serum.

\section{Transfusion of Whole Blood}

On the morning of Sept. 11, after the administration during the previous day and night of enough alkali to make the urine alkaline, the patient was given $500 \mathrm{c.cm}$. of a concentrated cell suspension of Group $O$ citrate-glucose blood within 90 minutes. Before the transfusion had been quite completed symptoms suggestive of a haemolytic episode began to make their presence felt. The patient complained of a slight dizziness and backache, and a little later felt sick. These symptoms slowly progressed but never became really severe, although there was some diarrhoea and sickness during the following night. Her temperature was slightly raised, the maximum being $100.2^{\circ} \mathrm{F}$. Within 24 hours of the transfusion the feeling of sickness abated and it seemed clear that the constitutional symptoms were subsiding. The patient had, however, by then become strikingly brownish-yellow in colour; the brownish tinge disappeared within a few days, but the jaundice persisted longer. Soon after the termination of the transfusion intense black urine was passed, and it continued in this state for the next 48 hours; but by the morning of Sept. 14 only a small amount of pigment was present, and the specimens passed on the 15th were clear. The urine then remained clear until Oct. 30.

The effect upon her blood is illustrated in the accompanying chart. This records $(a)$ the total erythrocyte level, $(b)$ the number of donor cells present, and $(c)$ the level of the patient's own cells after the transfusion $(a$ less $b$ ). The haemoglobin and reticulocyte percentages are also recorded and the presence or absence of haemoglobinuria and the results of the in vitro haemolysis test indicated. Study of the chart reveals several points of interest. The number of normal (donor) cells present after transfusion agreed well with expectations, there being a little more than 1 million per c.mm. This figure slowly and gradually fell, and approximately $18 \%$ of the transfused cells were still surviving 95 days after transfusion. This is essentially a normal rate of elimination (Mollison and Young, 1942). Despite the presence of 1 million per c.mm. or more of normal cells the total erythrocyte count had fallen slightly at the end of 24 hours, indicating great destruction of the patient's own cells -i.e., a fall from $2,370,000$ to $1,060,000$ per c.mm. The count remained at about the level of 1 million per c.mm. for 10 days or so and then rose fairly steadily, just reaching $2,500,000$ per c.mm. in six weeks. The total erythrocyte count, after falling about 300,000 per c.mm., reached its pre-transfusion level in 14 days and then steadily rose to $3,180,000$ per c.mm. four weeks later. The total count then slowly fell back to its pre-transfusion level of about $2,250,000$ per c.mm. The reticulocyte percentage followed the erythrocyte count in an inverse manner.

The percentage lysis observed in the standard in vitro tests was not significantly altered by the serum transfusions; after the blood transfusion there was a period of at least a week in which the sensitivity of the cells to lysis in vitro was clearly diminished even after making allowance for the presence of many normal cells. This may be due to the removal from the circulation of the most sensitive cells during the haemolytic crisis precipitated by the transfusion. It is interesting to note that sensitivity to the in vitro tests had been fully restored, and even appeared to be slightly increased, before the onset of haemoglobinuria, and that the latter did not reappear until the erythrocyte count had regained its pre-transfusion level. No doubt the présence of haemoglobinuria depends upon the renal threshold and the amount of haemoglobin liberated into the circulation per unit time, and is therefore more likely to be found at high rather than low levels of erythrocyte counts if the proportion of cells destroyed is a constant one.

\section{Discussion}

It is generally agreed that the basis of this strange disease is an undefined abnormality of the patient's erythrocytes which causes them to haemolyse in the presence of human serum both in vivo and in vitro (see Ham and Dingle, 1939). Our observations are consistent with this hypothesis and do not support any alternative theory ; in particular the possibility that the patient's erythrocytes were sensitized by the presence of an immune body or other haemolytic agent would appear to be negatived by the unimpaired survival of the transfused normal cells, unless it were assumed (without any evidence) that the hypothetical haemolytic agent was strictly autospecific.

Similarly, no evidence was forthcoming in support of the further possibility that lack of an antihaemolytic factor was responsible for the excessive breakdown of the patient's cells. Serum transfusions were without significant effect, and the ultimate rise in blood count following the blood transfusion appeared to be due to the good survival of the transfused cells. The patient's own cells did not increase significantly in numbers.

\section{Summary}

A short clinical description is given of a case of chronic haemolytic anaemia with nocturnal haemoglobinuria (Marchiafava-Micheli disease).

Two litres of stored normal serum was given intravenously within 12 days; no appreciable effect on, in vivo or in vitro haemolysis resulted.

A blood transfusion was followed by a severe haemolytic episode in which rather more than one-half of the patient's own erythrocytes were destroyed. The survival of the transfused blood was, however, unimpaired. The transfusion was followed by a remission from haemoglobinuria lasting 6 weeks.

The bearing of these observations on the pathogenesis of the disease is briefly discussed.

\section{REFERENCES}

Dacie, J. V., Israëls, M. C. G., and Wilkinson, J. F. (1938). Lancet, 1, 479. Ham, T. H.' (1937). New Engl. J. Med., 217, 915. 1939). Arch. intern. Med., 64, 1271.

- and Dingle, J. H. (1939). J. clin. Invest., 18, 657.

Hamburger, L. P., and Bernstein, A. (1936). Amer. J. med. Sci., 192, 301

Jordan, F. L. J. (1938). Acta med. scand., 95, 319.

Josephs, H. W. (1938). Johns Hopk. Hosp. Bull., 62, 25

Mollison, P. L., and Young, I. M. (1942), Quart. J. exp. Physiol., 31, 359.

Van den Bergh, A. A. H. (1911). Rev. Médecine, 31, 63.

\section{TREATMENT OF PSYCHIATRIC PATIENTS IN GENERAL HOSPITALS A SOCIAL EXPERIMENT \\ BY}

DALTON E. SANDS, M.R.C.P.Ed., D.P.M.

Deputy Medical Superintendent, Sutton Emergency Hospital

For centuries the peculiar symptoms of nervous and mental disorder have caused segregation to remain paramount over other aspects of treatment. This policy has been accepted, though with suspicion, by the main body of public opinion, but strongly resisted by individual patients and relatives. In Britain several thousands of patients are annually permitted to become chronic cases before specialized treatment is sought in a hospital for mental or nervous disorders because so many people, with or without good education, still regard these illnesses either as irrecoverable or to be treated conservatively at home as long as possible. Many a patient suffering from early psychosis could have avoided prolongation of illness, subsequent certification, and economic loss if either he or his relatives had not had the mistaken conception that on admission to hospital there was risk of being made worse by association with chronic patients, that active treatment scarcely existed, or that he would never be discharged. These ideas have their roots in the past, when the chief form of treatment known was to minister to the wellbeing of the patient on general lines as efficiently as overcrowding would allow. Under these conditions the better the quality of the personality the more likely was the individual to defer accepting hospital care, except in the most acute disorders.

Some idea of the cost of this policy may be gained from the estimation (Ebaugh, 1940) that, in the U.S.A., hospital beds are required for 100,000 patients becoming chronic annually, and in 1940 chronic psychiatric patients occupied half the total number of hospital beds. Many more are maintained in their own homes or in private nursing homes. The problem is little different in this country ; for example, the London County Council in accommodating their own share of the burden require, out of a total of 72,000 beds for all types of illness, 34,000 for psychiatric patients, a large majority of the beds being for chronic cases. Another aspect is shown by Sargant and Cook (1942), who reported that $20 \%$ of the cases admitted to the medical wards of a general hospital were found to present conditions and problems primarily neuropsychiatric, regardless of the patient's initial complaint or the preliminary diagnostic impression. 'Heldt (1940) also places the percentage at 20 or 30 , and remarks that if mention be made as well 
of all patients showing minor and secondary disturbances of nervous disorganization, then the figures rise still higher. Yet, with few exceptions, general hospitals refuse to admit, let alone attempt to treat, a nervous or mental patient if they know he has already been so diagnosed. In view of the incicence noted, the term "general hospital" seems scarcely a suitable one.

Hitherto the only widely organized in-patient treatment has been that afforded by the mental hospitals. In these there are six to eight doctors for 2,000 to 3,000 patients, a sufficiently high proportion if the patients are mostly chronic and in the days when the main treatment was custodial. In accommodation and classification there has been slow but steady improvement, and by legalizing voluntary admission, advocating special treatment villas for early patients, and establishing out-patient clinics, the Mental Treatment Act, 1930, brought many under treatment at an earlier stage, after the success of the Maudsley Hospital, London, and Jordanburn Hospital, Edinburgh, had emphasized the need for early voluntary accommodation. But even these hospitals have tended with time to become stigmatized as "mental," with its old-time implications, so that patients wait too long before accepting admission. Recently I have had opportunity to test the treatment of psychiatric patients in a general hospital neuropsychiatric ward, using modern methods already developed by psychiatrists, and I bslieve the results of this experiment allow some hope of easing this undesirable situation.

\section{Methods}

In discussing the results of a year's admissions (Table I) and the methods of this experiment, it must be stated that the 281 patients were all female, nearly all civilian, and of a selected type in that their personalities were relatively good

TABLE I.-Results (All Patients)

\begin{tabular}{|c|c|c|c|c|c|c|c|}
\hline \multirow[t]{2}{*}{$\cdot$} & \multirow[t]{2}{*}{ Grade } & & & \multicolumn{2}{|c|}{ On Discharge } & \multicolumn{2}{|c|}{$\begin{array}{l}\text { Follow-up } \\
\text { (2 to } 12 \text { Months) }\end{array}$} \\
\hline & & & & No. & $\%$ & No. & $\%$ \\
\hline $\begin{array}{l}\text { Recovered } \\
\text { Much impro } \\
\text { Improved } \\
\text { No change } \\
\text { Relapsed .. } \\
\text { Died .. }\end{array}$ & 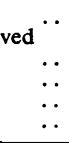 & $\begin{array}{l}\cdots \\
\cdots \\
\cdots \\
\cdots \\
\cdots\end{array}$ & $\begin{array}{l}\ldots \\
\cdots \\
\cdots \\
\cdots \\
\cdots\end{array}$ & $\begin{array}{l}98 \\
41 \\
93 \\
49 \\
- \\
-\end{array}$ & $\begin{array}{l}34 \cdot 8 \\
14 \cdot 5 \\
33 \cdot 3 \\
17 \cdot 4 \\
= \\
-\end{array}$ & $\begin{array}{r}100 \\
22 \\
79 \\
30 \\
13 \\
3\end{array}$ & $\begin{array}{r}40 \cdot 5 \\
8 \cdot 9 \\
32 \cdot 0 \\
12 \cdot 1 \\
5 \cdot 3 \\
1 \cdot 2\end{array}$ \\
\hline \multicolumn{3}{|c|}{$\begin{array}{l}\text { Total } \\
\text { Total number at work }\end{array}$} & $\begin{array}{l}\cdots \\
\cdots\end{array}$ & 281 & $100 \cdot 0$ & $\begin{array}{l}247 \\
189\end{array}$ & $\begin{array}{r}100 \cdot 0 \\
76 \cdot 5\end{array}$ \\
\hline
\end{tabular}

and likely to react favourably to modern treatment. A few were admitted in attempts to influence illness of long duration by recent methods, and in others considerable investigation, involving several departments of medicine, was necessary to elucidate the complicated problems presented. The unit consisted of two adjoining wards of 30 and 16 beds housed in a block of general wards. During a minor part of the time only the small ward was available. For administrative reasons the number of beds occupied was not allowed to exceed 40 , and the remaining space was used as dining accommodation for those convalescent. The wards had no side rooms, and differed in no way as regards restrictions from a general medical ward. The patients mixed with others from the medical and surgical wards at social functions and in the grounds. The medical staff consisted of two psychiatrists and very occasionally a third, all of whom had part-time duties in other parts of the hospital, including the special neurological unit. Nursing staff comprised a sister with general and psychiatric training and five nurses on each of the two daytime shifts.

The application of treatment facilities to selected patients on exactly the same basis as for medical and surgical patients showed clearly that $(a)$ many recoverable patients were failing to avail themselves of voluntary status in mental hospitals ; (b) many were unnecessarily losing jobs and suffering economic hardship. while their illness drifted into chronic invalidism or delayed recovery; $(c)$ with active treatment, comparable to that afforded to medical or surgical patients in general hospitals our patients were discharged with a combined recovered-andimproved rate of $82 \%$, maintained with a relapse rate on follow-up of only $5.3 \%$; and $(d)$ having been so treated for an average in-patient period of six weeks, over three-quarters of them were able to return to work soon after discharge.
In particular, 70 cepressive patients of various types treated by electro-convulsion therapy showed a discharge rate of $61.4 \%$ recovered, $35.6 \%$ improved or much improved, and $3 \%$ unchanged. Of 64 such patients followed up for an average of six months, $58 \%$ recovered, $33 \%$ improved or were much improved, and $9 \%$ relapsed $; 85.9 \%$ were at work. There were a number of milder cases of depression in which non-specific hospital treatment was sufficient to promote recovery. Results in the small group of 28 schizophrenics treated by insulin and/or electro-convulsion therapy were in accord with the encouraging figures for larger series of patients treated by modern methods, both on discharge and follow-up. Threequarters of these patients are now employed outside hospital. On this subject Ross et al. (1941) state that insulin produces an improvement significantly in excess of that obtained by any other means, and that after two years $75 \%$ of patients who were benefited had retained their improved state.

Our results (see Table I) were due to the following general scheme of treatment: Insulin comas* in early schizophrenia, electro-convulsions for depressions and some obsessional states, continuous sleep in acute anxiety neurosis, modified courses of insulin in anxiety hysteria with loss of weight, and prefrontal leucotomy for severe persistent obsessional states (which failed to react to other treatments). Psychotherapy in general or specialized form was used whenever it seemed indicated, coupled with psychological investigations under sodium amytal. Combined methods were most useful: physical methods and psychotherapy and sometimes two different physical methods have been used concurrently or successively on the same patient. (Reference has already been made to the application of these treatments in the male neurological unit of this hospital: Sargant, 1942.) In our series 9 courses of insulin coma were given, 115 of electrically induced convulsions, 28 of continuous sleep, and 94 of modified insulin; on 2 patients prefrontal leucotomy was performed, and 97 relatively specialized courses of psychotherapy were given. It has been necessary to support these measures by prompt examination of the patient, speed in instituting active treatment on the day of admission whenever possible, organized occupational therapy, and remedial exercises. By these practices such risks as those of suicide, which are inherent in treating acuter forms of psychiatric illness in an open ward, are greatly diminished, the patient becomes amenable to the efforts of the nursing staff at an early stage, and the morale of those more advanced in treatment is unimpaired. To obtain the best results one must be prepared to modify the technique and routine of treatment to suit the individual, and on discharge to give such medical recommendation as will assist resettlement in work. With the co-operation of the Ministry of Labour employment was modified in many instances to suit individual needs. In fact, general hospital psychiatric treatment has become possible because in the last three years treatment has developed sufficiently to achieve good clinical results and early control of symptoms in nearly all the numerous patients of the type reported here, without blocking beds for an unduly long period.

In all patients, duration of illness varied from one week to seventeen years, averaging one year and eleven months. In actuality, nearly three-quarters of the patients had been ill for a year or less. The average duration was somewhat distorted on account of a small group of patients admitted partly by reason of the very length of illness. Half the patients were classified as psychoses, including 111 depressives of various types and 28 sçhizophrenics ; $38 \%$ suffered from neuroses; and other organic conditions comprised the remainder. Thirty-one psychotic and six neurotic cases were relatively acute ; in only six of these was it impossible to control symptoms by treatment, and with the co-operation of the relatives they were discharged for admission to observation wards. It will therefore be noted that the most extremely disturbed patients were not nursed in our ward. The proportion discharged against advice-under 7\%-seems reasonably low considering how often these patients are indecisive, suspicious, and liable to take an unreasonable course of action.

The fact that psychoses often drift on into chronicity has led to a tradition that the prognosis generally is gloomy. This view is certainly unjustified when modern methods are employed

* Since the period under review the use of insulin therapy has increased. 
for suitable patients. In our material the psychotics did better than the neurotics, both in their reaction to treatment and in the maintenance of improvement gained (Table II), with

TABLE II.-Comparison of Results in Neurotics and Psychotics

\begin{tabular}{|c|c|c|c|c|c|c|c|c|c|c|c|c|}
\hline \multirow[b]{2}{*}{ Diagnosis } & \multicolumn{5}{|c|}{ On Discharge } & \multicolumn{7}{|c|}{ Follow-up ( 2 to 12 Months) } \\
\hline & $\mathbf{R}$ & MI & I & NC & Total & $\mathbf{R}$ & MI & I & NC & Rel & Total & \begin{tabular}{|c|} 
At \\
Work
\end{tabular} \\
\hline $\begin{array}{l}\text { Neuroses: } \\
\text { No. } \quad \because \\
\%\end{array}$ & $\begin{array}{l}26 \\
26\end{array}$ & $\begin{array}{l}18 \\
18\end{array}$ & $\begin{array}{l}42 \\
42\end{array}$ & $\begin{array}{l}14 \\
14\end{array}$ & 100 & $\mid \begin{array}{l}29 \\
30.5\end{array}$ & $\begin{array}{l}8 \\
8 \cdot 4\end{array}$ & $\begin{array}{l}41 \\
43 \cdot 2\end{array}$ & $14 \cdot 2$ & 23 & 95 & $\begin{array}{l}68 \\
71 \cdot 5\end{array}$ \\
\hline $\begin{array}{l}\text { No. } \\
\%\end{array}$ & $\begin{array}{l}63 \\
50 \cdot 4\end{array}$ & $\begin{array}{l}20 \\
16\end{array}$ & $24 \cdot$ & ${ }_{8.8}^{11}$ & 125 & $\begin{array}{l}58 \\
50 \cdot 4\end{array}$ & $\begin{array}{l}17 \\
14 \cdot 8\end{array}$ & $\begin{array}{l}22 \\
19 \cdot 1\end{array}$ & $\begin{array}{l}10 \\
8.7\end{array}$ & $\begin{array}{l}8 \\
7\end{array}$ & 115 & $\begin{array}{l}89 \\
77 \cdot 4\end{array}$ \\
\hline
\end{tabular}

$R=$ Recovered; $M I=$ Much improved; I=Improved; $N C=$ No change; Rel = Relapsed.

*Average stay: Neuroses, 45.7 days; Psychoses, 47.1 days.

a negligible difference in time required in hospital. The, view expressed in the British Medical Journal leader of Oct. 3, 1942, (p. 397) concerning the favourable outlook in the recent acute psychotics compared with the neurotics has been fully confirmed. The reason for these findings partly lies in the fairly good pre-psychotic personalities of many patients selected for admission to this ward, in their comparative youth (average age 33 years), and in the fact that they were under specialized hospital care at an earlier stage in their illness than is usually possible in mental hospitals. If it were generally realized how effective can be the speedy treatment of an early patient by the skilled use of modern methods individually applied, years of illness and invalidism could often be averted. For instance, Rivers and Bond (1941) showed that a skilled insulin therapist can raise the recovered-much-improved rate on discharge in schizophrenics as high as $79 \%$ for patients treated within the first year of illness. If insulin is given by inexperienced therapists they show that the figure only reaches $46 \%$ in the same type of patient. They state also that, irrespective of duration of illness, $63 \%$ of the more skilfully treated patients recovered or greatly improved, as compared with less than $10 \%$ in preinsulin days. If left untreated some of our patients would undoubtedly have had to enter mental hospitals at a later date. In others the personality was sufficiently adjusted for them to stay at home at the price of long invalidism and economic dependence.

\section{Commentary}

This experiment in hospital procedure offers advantages for patients, the medical profession, and the administrative services. Patients and relatives appreciated active treatment in a general hospital instead of the unfamiliar mental hospital. On discharge their social readjustment and employment presented less difficulty than if associates or employers were aware of recent mental hospital care. Even the large depressive and smaller schizophrenic groups, the very nature of whose illness has sometimes precluded acceptance of early in-patient mentalhospital treatment even under voluntary status, often sought and nearly always accepted active treatment in, a general hospital neuropsychiatric ward. The patients have shown that this type of ward is a most promising weapon for combating the so-called stigma of mental illness, and I believe it can hasten public acceptance of sufferers from nervous or mental disorder as sick yet frequently recoverable people as nothing has hitherto. Provision of this form of treatment offers hope of diminishing the suicide rate in early sufferes from mental disorder. In a U.S. hospital psychiatric ward there were but two suicides in nearly four years, as opposed to three in other wards. Another psychiatric ward had none in six years.

For the profession, and especially for students, these patients are a valuable source of teaching material, contrasting strongly with the standardized display of end-results, vivid in symptoms but poor in prognosis. Their study and investigation can provide a very necessary increase of research workers and clinicians skilled in both physical and psychotherapeutic methods, and can equip the young general practitioner with the psychiatric understanding required by 30 to $60 \%$ of the symptoms shown by his patients. Similar improvements can be obtained in the quality and status of the nursing staff. Psychiatry demands expert and intelligent nursing, because the safety and success of such physical methods as insulin comas or continuous narcosis depend on the efficiency of the nurse in charge.
Most general practitioners dislike certifying any of their patients or having to send them to observation wards against their wishes. Occasionally there is the threat of legal action by resentful patients or relatives. Timely use of the general hospital psychiatric ward can solve many of these problems.

The advantage of ready access to specialist opinion for securing early neuropsychiatric diagnosis has been shown by Sargant and Cook (1942), particularly with regard to shortening the patient's time in hospital and saving innumerable laboratory investigations and much maintenance expense. In this hospital such assistance has been part of the service rendered to the general medical and surgical wards in return for their advice on our patients, obtained on 94 occasions.

For administrative services there have been two main advantages: (1) At least 16 hospitals in the London area have used the psychiatric facilities afforded. Had more accommodation been possible it could easily have been filled. (2) In financial economy, compare the treatment of any early case of schizophrenia by insulin shock in an eight-weeks period at the L.C.C. peacetime general hospital rate of $£ 310 \mathrm{~s}$. a week with the frequent care of the chronic patient at the menta hospital rate averaging $£ 19$ s. for five years-i.e., $£ 28$ to $£ 377$. If total chronicity occurs from lack of early treatment the cost rises to $£ 2,600$ for 25 years. The potential financial saving inherent in our own and Rivers and Bond's results, noted above, is therefore particularly impressive. These economies have occurred with the use of unpretentious temporary wartime accommodation, and apart from minor adjustments no unusual or elaborate structures are required.

In a small-scale test this experiment has shown many definite advantages, but it certainly raises its own problems. For instance, to what extent can mental hospital services, at present largely organized to meet the maintenance needs of an abundance of chronic patients, be adjusted to secure the confidence of the early-recoverable patient, so that this confidence would lead to their early treatment and lessen the incidence of chronicity? In common with some mental hospitals we find modern therapeutic methods to be of much assistance in this respect.

There is no doubt that extensive reorganization of mental health facilities, already under discussion, can disperse many of the present objections. Its full realization is likely to be a matter of several years. Meanwhile, the combination of outpatient clinic, mental hospital, and general hospital neuropsychiatric unit suggests a practical basis for a more comprehensive mental health service, calculated to supply early treatment in a form acceptable to many potentially recoverable patients as well as relief to the more chronic types of illness.

\section{Summary}

Investigation has been made of 281 patients selected for psychiatric treatment in a general hospital during a year. After an average in-patient period of six weeks, over three-quarters were able to return to work, the usual length of illness having been greatly shortened and chronicity avoided in many cases. Clinical recovery and improvement on discharge $(82 \%)$ was maintained on follow-up, with loss of $5 \%$ relapsed. The scheme of modern psychiatric treatment used is described.

The experiment has been discussed in relation to therapeutic, professional, financial, and other fields.

I wish to express my sincere thanks to Dr. Louis Minski, medical superintendent; and to Dr. E. T. O. Slater for most helpful criticism and advice; also to Dr. W. Sargant for advice on physical methods of treatment, and to Dr. H. J. Shorvon, Sister E. A. Gaunt Murphie, and Miss J. M. Moore for their valuable assistance.

British Medical Journal, 1942, 2, 397.

$$
\text { REFERENCES }
$$

Ebaugh, F. G. (1940). Care of the Psychiatric Patient in General Hospitals, Amer. Hosp Ass. Chicago, III.

Heldt (1940). Ibid.

Rivers, T. D., and Bond, E. D. (1941). Amer. J. Psychiat., 98, 382.

Ross, J. R., et al. (1941) Ibid., 97, 1007.

Sargant, W., (1942). British Medical Journal, 2, 574.

and Cook, G. (1942). Lancet, 1, 31.

F. W. Taylor (J. Amer. med. Ass., 1942, 118, 1196) observes that chronic ulcers of the limbs, predominantly of the legs, due to infection with a haemolytic streptococcus have received little attention. The lesion is chronic and similar to that of varicose ulceration, and is usually seen in children and young adults with no apparent vascular abnormality. The 19 cases he describes responded well to sulphanilamide by mouth. 